\title{
Levo(-) amphetamine and dextro(+) amphetamine in the treatment of narcolepsy
}

\author{
J. D. PARKES AND G. W. FENTON
}

From the University Department of Neurology, Institute of Psychiatry, and King's College Hospital and the Department of Clinical Neurophysiology, The Maudsley Hospital, Denmark Hill, London

SUMMARY The narcoleptic syndrome is a life-long and sometimes familial disorder in which there is a disturbance of the rapid eye movement phase of sleep. Patients with periodic sleep in the daytime but no other symptoms seldom develop the narcoleptic syndrome and have a separate unrelated disorder. Twelve patients with the narcoleptic syndrome were treated separately with $1(-)$ amphetamine and $\mathrm{d}(+)$ amphetamine. Both drugs abolished narcolepsy, $\mathrm{d}(+)$ amphetamine being slightly more potent than $1(-)$ amphetamine. In equipotent doses, unwanted effects of nervousness and insomnia were equal in frequency. No tolerance to either preparation developed during a six month period. Cataplexy was not affected by amphetamine treatment, but was abolished in two patients when clomipramine was given together with either amphetamine.

The treatment of narcolepsy by amphetamines was established by Prinzmetal and Bloomberg in 1935. As a high dosage is often required, toxic effects occur which include insomnia, nervousness, tremor, hypertension, hyperpyrexia and, rarely, acute paranoid psychosis (Connell, 1958). Amphetamine tolerance and addiction, however, are uncommon (Goodman and Gilman, 1970). Evidence has been presented which indicates that $\mathrm{d}(+)$ amphetamine is twice as potent as the racemic mixture of $\mathrm{d}(+)$ and $1(-)$ amphetamine, suggesting that $1(-)$ amphetamine itself is inactive (Martindale and Westcott, 1967). L(-) amphetamine has, however, been used successfully by Passouant and his colleagues to treat patients with narcolepsy who have not responded to $\mathrm{d}(+)$ amphetamine or in whom this isomer caused dose-limiting unwanted effects (Passouant et al., 1964; Schwab and Passouant, 1964). Because of this apparent controversy and as the two amphetamine isomers have different biochemical and behavioural effects (Snyder et al., 1970; Taylor and Snyder, 1970), we have reinvestigated the use of $\mathrm{d}(+)$ and $\mathrm{l}(-)$ amphetamine in treating patients with the narcoleptic syndrome. 
withdrawal of medication. The patients found it difficult to give an accurate subjective account of the frequency and duration of their sleep attacks, which were confirmed by witnessed accounts in eight patients. Untreated patients had from two to 11 narcoleptic attacks each day (mean, seven) lasting from 5 to 60 minutes (mean, 19 minutes). Sleep attacks were most frequent during the afternoon and evening and many occurred while travelling, reading, watching television, sitting, or eating. Eight patients also had cataplexy. In these head nodding was common, occurring daily in two patients. Momentary immobility was less common and complete lapses of posture with falling were rare, occurring at most one or two times each month. Three patients had episodic double vision with laughter, one of whom described horizontal object separation. A further patient complained of episodic difficulty in focusing with ptosis. Five patients, four of whom had cataplexy, also had hypnagogic hallucinations which included visions of falling through space and of being chased, dreams of concentration camps, and the desolation of war. Eight patients had infrequent sleep paralysis.

No patient had a family history of the narcoleptic syndrome, but the paternal uncle of one patient suffered from narcolepsy without other features. None suffered from chronic bronchitis or other respiratory illness and there was no history of abnormal thirst or obesity. The findings on clinical examination of all patients were normal and no patient had blackouts or showed electroencephalographic features suggesting epilepsy.

MEDICATION Pre-trial medication Three patients were taking $\mathrm{d}(+)$ amphetamine sulphate $(10,15$, and $20 \mathrm{mg} /$ day respectively) and another took methylphenidate $(60 \mathrm{mg} / \mathrm{day})$ before this trial. Their treatment was stopped for one week and the patients were warned of possible drowsiness. All complained of an increased number of narcoleptic attacks during this withdrawal period and one patient complained of considerable increase in appetite.

Phase I-l(-) amphetamine and placebo The activity of $1(-)$ amphetamine was compared with placebo during a three week period. All patients took a placebo preparation in the first week. Either $1(-)$ amphetamine or placebo was given in the second week (double-blind) and the order of administration was reversed in the third week. The dose of $1(-)$ amphetamine was $40 \mathrm{mg}$ daily in $10 \mathrm{mg}$ capsules taken at 7.30,12,15.30, and 19.30 hours. Placebo capsules contained maize stearate (BP) $10 \mathrm{mg}$, lactose (BP) $335 \mathrm{mg}$, and magnesium stearate (BP) $5 \mathrm{mg}$.
Phase II-Relative potencies of $l(-)$ amphetamine and $d(+)$ amphetamine The relative potency of $20 \mathrm{mg}$ of each amphetamine isomer was determined during the following two weeks. Each was given separately (double-blind) in two divided doses of $10 \mathrm{mg}$ taken at 7.30 and 12.00 hours for one week followed by a week of the other medication. Five patients gave a subjective preference for $1(-)$ amphetamine and seven for $\mathrm{d}(+)$ amphetamine.

Phase III-Long-term $l(-)$ amphetamine and $d(+)$ amphetamine therapy Each patient was given the amphetamine isomer they preferred in the comparison above. The optimum dosage was established and found to be: levoamphetamine $20-60 \mathrm{mg} / \mathrm{day}$, dextroamphetamine $10-45 \mathrm{mg} /$ day.

PATIENT ASSESSMENT On clock-face diagrams patients recorded the onset and duration of day and night sleep periods during each Tuesday and Thursday. They noted cataplexy, sleep paralysis, hypnagogic hallucinations, and double vision and stated the treatment period preferred. Unwanted sideeffects including tremor, nervousness, palpitations, and insomnia were recorded, and the blood pressure, pulse rate, and temperature were recorded at weekly intervals during the trial.

ELECTROENCEPHALOGRAPHIC RECORDINGS The electroencephalogram (EEG) was recorded twice on eight patients during placebo and levoamphetamine treatment at 15.30-16.30 hr. Electrode placement and recording techniques were standardized and the onset and duration of sleep-periods were determined from the first $\mathbf{4 0}$ minutes of recording period by the methods of Rechtschaffen and Kales (1968).

URINARY AMPHETAMINE DETERMINATION A 24 hOur urine sample taken during the period of $1(-)$ amphetamine treatment was analysed for $1(-)$ and $\mathrm{d}(+)$ amphetamine content. The method used was the gas-liquid chromatographic separation of $1(-)$ and $\mathrm{d}(+)$ amphetamine from urine after derivatization with the optically active reagent $\mathrm{N}$-trifluoroacetyl-L-propyl chloride to form a distereoisomeric pair (Beckett and Tester, 1972).

CLOMIPRAMINE TREATMENT OF CATAPLEXY CatapleXY did not respond to either amphetamine isomer. Two patients who were disabled by this symptom were given clomipramine $25 \mathrm{mg}$ twice daily together with $\mathrm{d}(+)$ amphetamine $(2.5 \mathrm{mg} /$ day $)$ in one patient and $1(-)$ amphetamine $(10 \mathrm{mg} /$ day $)$ in the other. 


\section{RESULTS}

L(-) amphetamine AND Placebo The frequency and duration of narcoleptic attacks during periods of placebo treatment and in untreated patients were similar. $\mathrm{L}(-)$ amphetamine $40 \mathrm{mg} /$ day reduced the frequency of these attacks $(\mathrm{P}<0.01)$; there were none in nine patients and a reduced occurrence in both frequency and duration in the other three (Table 1). Cataplexy, hypnagogic hallucinations, and double-vision were all reported to approximately the same extent during both placebo and $1(-)$ amphetamine treatment.

TABLE 1

RESPONSE OF PATIENTS WITH NARCOLEPSY TO PLACEBO AND L(-) AMPHETAMINE 40 MG/DAY

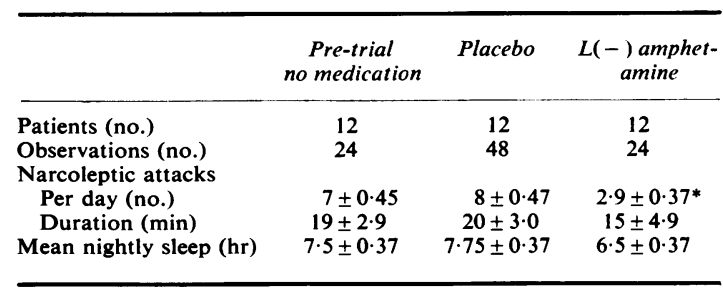

Mean values \pm 1 SEM.

$* \mathrm{l}(-)$ amphetamine better than placebo, $\mathbf{P}<0.01$.

Eleven patients gave a subjective preference for the $1(-)$ amphetamine period compared with placebo and one patient had no preference. All were taking $1(-)$ amphetamine during the appropriate period as shown by the gas-liquid chromatographic results. $\mathrm{D}(+)$ amphetamine was not detected in the urine samples. The unwanted effects reported are shown in Table 2. Five patients complained of insomnia while on 1(-) amphetamine. Nervousness, sweating, and palpitations were recorded during both placebo

TABLE 2

UNWANTED EFFECTS OF AMPHETAMINE TREATMENT*

\begin{tabular}{lcccc}
\hline & Placebo & $\begin{array}{c}L(-) \\
\text { amphetamine } \\
(40 \mathrm{mg} / \text { day })\end{array}$ & $\begin{array}{c}L(-) \\
\text { amphetamine } \\
(20 \mathrm{mg} / \text { day })\end{array}$ & $\begin{array}{c}D(+) \\
\text { amphetamine } \\
(20 \mathrm{mg} / \text { day })\end{array}$ \\
\hline Insomnia & 0 & 5 & 0 & 3 \\
Nervousness & 5 & 4 & 0 & 2 \\
Sweating & 1 & 1 & 1 & 0 \\
Palpitation & 1 & 1 & 0 & 1 \\
Tremor & 0 & 1 & 1 & 3 \\
\hline
\end{tabular}

* The number of patients complaining of each side-effect is shown. and $1(-)$ amphetamine treatment. There was no significant change in mean pulse rate, body temperature, or blood pressure, during either the initial $1(-)$ amphetamine treatment or at the end of six months.

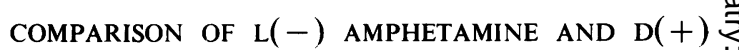
AMPHETAMINE $\mathrm{D}(+)$ amphetamine was slightly more effective than $1(-)$ amphetamine in abolishing narcolepsy, but this difference was not statistically significant $(P>0.05)$. Three patients had narcoleptic attacks on both amphetamines, a further three patients had no attacks while taking dextroamphetamine, and six reported no narcoleptic attacks with either isomer (Table 3). Cata-

\section{TABLE 3}

RESPONSE OF PATIENTS WITH NARCOLEPSY TO $L(-)$ AMPHETAMINE AND $\mathrm{D}(+)$ AMPHETAMINE 20 MG/DAY

\begin{tabular}{lcc}
\hline & $\begin{array}{c}L(-) \\
\text { amphetamine } \\
(20 \mathrm{mg} / \text { day })\end{array}$ & $\begin{array}{c}D(+) \\
\text { amphetamine } \\
(20 \mathrm{mg} / \text { day }\end{array}$ \\
\hline $\begin{array}{l}\text { Narcoleptic attacks/day (no.) } \\
\text { Duration of narcoleptic attack (min) } \\
\text { Total night sleep period (hr) }\end{array}$ & $\begin{array}{c}2.1 \pm 0.43 \\
15 \pm 3.9\end{array}$ & $\begin{array}{c}1.4 \pm 0.31 \\
15 \pm 2.4 \\
\end{array}$ \\
\hline
\end{tabular}

Mean values \pm 1 SEM. The mean differences between $\mathrm{I}(-)$ ampheg amine and $d(+)$ amphetamine are not significant $(P>0.05)$.

plexy, hypnagogic hallucinations, and doublevision were not affected by either preparation; sleep paralysis was not recorded during this trial. Seven patients gave a subjective preference for $\mathrm{d}(+)$ amphetamine and five patients for $1(-)$ amphetamine at the end of this phase.

LONG-TERM AMPHETAMINE THERAPY The daily number of narcoleptic attacks at the end of a six month treatment period with either $1(-)$ amphetamine or $\mathrm{d}(+)$ amphetamine was similar to that in phase II. One patient required adjustment of $1(-)$ amphetamine dosage during this six month period, increasing after three months from 40 to $50 \mathrm{mg} /$ day. No new side-effects were reported.

ELECTROENCEPHALOGRAPHIC RECORDING Every patient went to sleep during both placebo and l(-) amphetamine treatment (Table 4). The N majority of time was spent in stages 1 and 2 of sleep. Stages 3 and 4 were rare, as was rapid eye 
TABLE 4

EEG CHANGES IN PATIENTS WITH NARCOLEPSY

\begin{tabular}{lcc}
\hline & Placebo & L( - ) amphetamine \\
\hline Wakefulness (W) & $12 \cdot 1$ & $10 \cdot 1$ \\
Total sleep time (TST) & 27.9 & 29.9 \\
Stage of sleep & & \\
I & 14.2 & 8.5 \\
II & 16.0 & 19.5 \\
III & 1.0 & 2.7 \\
IV & 0 & 0.1 \\
REM sleep & 0.6 & 1.1 \\
Latency of onset of sleep (min) & 10.9 & $5 \cdot 8$ \\
\hline
\end{tabular}

Mean duration of wakefulness and sleep periods ( $\mathrm{min}$ ) in eight patients with the narcoleptic syndrome. Sleep latency defined as interval between recording onset and first occurrence of $1 \mathrm{~min}$ stage 1 or deeper sleep. No difference between placebo and $1(-)$ amphetamine treatment period is significant ( $P>0.05$, Wilcoxon's signed rank test).

movement (REM) sleep, which occurred in only three subjects, during the $1(-)$ amphetamine period in one patient and during placebo treatment in two. The first type of sleep in every patient was stage 1 and never REM. The latency of onset of sleep was very variable during both placebo and $1(-)$ amphetamine treatment (range on placebo $0-33.7$ minutes; on $1(-)$ amphetamine 0-21 minutes).

CLOMIPRAMINE TREATMENT OF CATAPLEXY Clomipramine abolished cataplexy in the two patients to whom it was given. Both of these previously had occasional sleep paralysis and hypnagogic hallucinations which also responded to this treatment. Clomipramine had no beneficial affect upon narcolepsy and caused slight persistent drowsiness at the commencement of treatment. Blood pressure and pulse rate were not changed by the addition of clomipramine.

\section{DISCUSSION}

The narcoleptic syndrome of drowsiness, cataplexy, sleep-paralysis, and hypnagogic hallucinations is not uncommon, but all four symptoms are present in only a third of patients (Wolfenden, 1969). Double vision or momentary focusing difficulty with ptosis is sometimes the only evidence of cataplexy. The syndrome is a life-long disorder and the prognosis for recovery is poor (Prull, 1963). Both narcolepsy and cataplexy are occasionally familial; only one of the present patients had an affected relative (Daly and Yoss, 1959; Gelardi and Brown, 1967). Narcolepsy has been described in patients with disseminated sclerosis and a variety of tumours of the nervous system which are mainly in the periventricular grey matter and neighbouring parts of the diencephalon and mesencephalon (Berg and Hanley, 1963; Tridon et al., 1969).

However, in most of these cataplexy was not present or narcolepsy was an incidental finding. Some patients with narcolepsy also have epilepsy (Symonds, 1954), but in those described here, neither epilepsy nor evidence of structural damage to the nervous system was present. The familial occurrence, absence of constant pathological basis, and lifelong nature of the narcoleptic syndrome is consistent with a specific biochemical disorder.

The REM phase of sleep is abnormal in patients with the narcoleptic syndrome (Rechtschaffen et al., 1963). Night sleep starts with a REM phase. This suggests that the narcoleptic syndrome is unrelated to the condition of excess drowsiness without other symptomatology. The latter patients have normal REM sleep and rarely develop the narcoleptic syndrome (Passouant et al., 1968). Amphetamines suppress REM sleep (Rechtschaffen and Marron, 1964), and this may account for their action in narcolepsy, rather than any stimulant effect on the central nervous system; phenelzine which abolishes REM sleep also abolishes narcolepsy (Wyatt et al., 1971). Despite the action of $1(-)$ amphetamine in reducing the frequency of narcoleptic attacks, the EEG evidence suggests that the drug has no effect on the EEG patterns of narcoleptic diurnal sleep.

The precise relationship between narcolepsy and cataplexy is uncertain, but there is a reduction in muscle tone during sleep and particularly in REM sleep (Hishikawa et al., 1965). Stimulation of closely related centres in the animal brain produces either REM sleep or muscular paralysis (Jouvet and Delorme, 1965).

However, during an attack of cataplexy, the patient is clearly not asleep and the EEG record shows wakefulness (Hishikawa and Kaneko, 1965). This distinction between narcolepsy and cataplexy is shown also by the action of amphetamine on the first and clomipramine on the second.

Amphetamines affect catecholamine stores in the central nervous system (Carlsson et al., 1965), 
but each isomer has a different effect. $\mathrm{D}(+)$ amphetamine is 10 times as potent as $1(-)$ amphetamine in inhibiting the accumulation of noradrenaline in nerve terminals, but both forms are equiactive on dopamine accumulation in selected brain regions (Taylor and Snyder, 1970). $\mathrm{D}(+)$ amphetamine is 10 times as potent as $1(-)$ amphetamine in causing motor hyperactivity in rats, but only one to two times as potent in causing stereotyped behaviour (Snyder et al., 1970). This agrees with the view that dopamine rather than noradrenaline is associated with stereotyped behaviour, while hypermotility may be related more to noradrenaline (Randrup and Scheel-Krüger, 1966). The relative potency of the amphetamine isomers in narcolepsy would thus be consistent with an action on cerebral dopamine rather than on noradrenaline. However, the toxic effects of both amphetamines mimic those of adrenaline, since anxiety, restlessness, palpitations, and tremor occur and not nausea and vomiting. Both drugs control narcolepsy, though, as they may have a different therapeutic index, if toxic symptoms result from $\mathrm{d}(+)$ amphetamine, $1(-)$ amphetamine is worth trial. If cataplexy is disabling, the addition of imipramine or clomipramine is often successful (Akimoto et al., 1960; Passouant et al., 1970).

We are most grateful to Dr. Alan Galbraith and Geigy (U.K.), for the preparation and gift of $1(-)$ amphetamine used in this study. Dr. Bernard Testa, Chelsea College, University of London, performed the amphetamine assays and Miss $\mathrm{C}$. Casemore, Miss O. Stokan, Mrs. D. Battye, and Miss M. O'Rourke gave valuable assistance.

\section{REFERENCES}

Akimoto, H., Honda, Y., and Takahashi, Y. (1960). Pharmacotherapy in narcolepsy. Diseases of the Nervous System, 21, 704-706.

Beckett, A. H., and Testa, B. (1972). Stereochemical separation and configurational assignment by gas-liquid chromatography. Journal of Chromatography, 69, 285-289.

Berg, O., and Hanley, J. (1963). Narcolepsy in two cases of multiple sclerosis. Acta Neurologica Scandinavica, 39, 252-257.

Carlsson, A., Lindqvist, M., Dahlström, A., Fuxe, K., Masuoka, D. (1965). Effects of the amphetamine group on intraneuronal brain amines in vivo and in vitro. Journal of Pharmacy and Pharmacology, 17, 521-524.

Connell, P. H. (1958). Amphetamine Psychosis. Maudsley Monograph No. 5. Chapman and Hall: London.

Daly, D. D., and Yoss, R. E. (1959). A family with narcolepsy. Proceedings of the Staff Meetings of the Mayo Clinic
34, 313-320.

Gelardi, J.-A. M., and Brown, J. W. (1967). Hereditary cataplexy. Journal of Neurology, Neurosurgery, and Psychiatry, 30, 455-457.

Goodman, L. S., and Gilman, A. (eds) (1970). The Pharmacological Basis of Therapeutics. 4th edn, p. 518. Macmillan: New York.

Hishikawa, Y., and Kaneko, Z. (1965). Electroencephalographic study on narcolepsy. Electroencephalography and Clinical Neurophysiology, 18, 249-259.

Hishikawa, Y., Sumitsuji, N., Matsumoto, K., and Kaneko, Z. (1965). H-reflex and EMG of the mental and hyoid muscles during sleep, with special reference to narcolepsy. Electroencephalography and Clinical Neurophysiology, 18, 487-492.

Jouvet, M., and Delorme, F. (1965). Locus coeruleus et sommeil paradoxal. Comptes Rendus des Séances de la Société de Biologie, 159, 895-899.

Martindale, W., and Westcott, W. W. (1967). The Extra Pharmacopoeia, Martindale. 25th edn, p. 101. Pharmaceutical Press: London.

Passouant, P., Baldy-Moulinier, M., and Aussilloux, C. (1970). État de mal cataplectique au cours d'une maladie de Gélineau; influence de la clomipramine. Revue Neurologique, 123, 56-60.

Passouant, P., Popoviciu, L., Velok, G., and Baldy-Moulinier, 'ं M. (1968). Étude polygraphique des narcolepsies au cours du nycthémère. Revue Neurologique, 118, 431-441.

Passouant, P., Schwab, R. S., Cadilhac, J., and Bald Moulinier, M. (1964). Narcolepsie-cataplexie. Étude do sommeil de nuit et du sommeil de jour. Traitement par ure amphétamine lévogyre. Revue Neurologique, 111, 415-426

Prinzmetal, M., and Bloomberg, W. (1935). The use of benzedrine for the treatment of narcolepsy. Journal of th American Medical Association, 105, 2051-2054.

Prüll, G. (1963). Katamnestische Erhebungen und therâ. peutische Erfahrungen bei Narkolepsiekranken. Nerves arzt, 34, 480-484.

Randrup, A., and Scheel-Krüger, J. (1966). Diethyldithiocarbamate and amphetamine stereotype behaviour. Journal of Pharmacy and Pharmacology, 18, 752.

Rechtschaffen, A., and Kales, A. (eds) (1968). A Manual of Standardized Terminology, Techniques and Scoring System for Sleep Stages of Human Subjects. National Institutes of Health Publication No. 204, p. 57. U.S. National Institute of Neurological Diseases and Blindness: Bethesda, Md.

Rechtschaffen, A., and Maron, L. (1964). The effect of $\underset{F}{F}$ amphetamine on the sleep cycle. Electroencephalography and Clinical Neurophysiology, 16, 438-445.

Rechtschaffen, A., Wolpert, E. A., Dement, W. C., Mitchell, S. A., and Fisher, C. (1963). Nocturnal sleep of narcoleptics. Electroencephalography and Clinical Neurophysiology, 15, 599-609.

Schwab, R.-S., and Passouant, P. (1964). Scientific Exhibit at the American Neurological Association, Atlantic City, New Jersey, 15-17 June 1964.

Snyder, S. H., Taylor, K. M., Coyle, J. T., and Meyerhoff, J. L. (1970). The role of brain dopamine in behavioral regulation and the actions of psychotropic drugs. American Journal of Psychiatry, 127, 199-207.

Symonds, Sir C. (1954). Cataplexy and other related forms of seizure. Canadian Medical Association Journal, 70, 621-음 625.

Taylor, K. M., and Snyder, S. H. (1970). Amphetamine: N differentiation by $\mathrm{d}$ and $\mathrm{l}$ isomers of behavior involving brain norepinephrine or dopamine. Science, 168, 14871489. 
Tridon, P., Montaut, J., Picard, L., Weber, M., and André, J. M. (1969). Syndrome de Gélineau et hémangioblastome kystique du cervelet. Revue Neurologique, 121, 186-189.

Wolfenden, W. H. (1969). Narcolepsy. Bulletin of the PostGradıate Committee in Medicine, University of Sydney, 25, 64-68.
Wyatt, R. J., Fram, D. H., Buchbinder, R., and Snyder, F. (1971). Treatment of intractable narcolepsy with a monoamine oxidase inhibitor. New England Journal of Medicine, 285, 987-991.

Yoss, R. E., and Daly, D. D. (1957). Criteria for the diagnosis of the narcoleptic syndrome. Proceedings of the Staff Meetings of the Mayo Clinic, 32, 320-328. 